\title{
ABSENCE OF METATHORACIC WINGS AND CORRECTIONS TO THE DESCRIPTION OF CHAETOCNEMA LABIOSA WHITE, 1996 (COLEOPTERA: CHRYSOMELIDAE)
}

\author{
Shawn M. Clark ${ }^{1}$ and Robert L. Johnson ${ }^{2}$
}

\begin{abstract}
Aвstract-Corrections and additions to the original description of Chaetocnema labiosa White are given and include the report of characters associated with the loss of flight. New distributional data are provided. Possible host plants and the likelihood of parthenogenetic populations are briefly discussed.
\end{abstract}

Key words: Chaetocnema labiosa, Chrysomelidae, aptery, parthenogenesis.

In his superb taxonomic revision of the flea beetle genus Chaetocnema Stephens for America north of Mexico, White (1996) described a new species, C. labiosa, based on 30 specimens from only 8 sites in California, Colorado, Idaho, Nevada, and Utah. We have recently collected this species or have examined museum specimens from a number of additional sites, including specimens from a remarkable aggregation in Utah. Based on our discoveries, we present corrections and additions to the original description, new distribution data, and remarks on flightless and possibly parthenogenetic populations.

Chaetocnema labiosa is quite distinctive in its appearance (Fig. 1). Experienced workers are not likely to confuse it with any other species, in spite of diagnostic key problems discussed below. It is most similar to C. densa White. Close inspection enables easy separation of even these 2 species, based on characters given by White (1996). Comparatively coarse punctures on the vertex of $C$. densa are numerous and easily visible under normal magnification, and they approach the midline, leaving a rather narrow, impunctate median strip. In C. labiosa, only a few coarse punctures are present near each eye, and the more medial punctures are minute and somewhat hidden among the reticulate microsculpture. The bilobed labrum of C. labiosa (Fig. 3) is distinctive and apparently unique among described North American Chaetocnema.

In several instances, White (1996) either described characters for C. labiosa that are contrary to the specimens we examined, or he did not mention characters that are distinctive. We therefore borrowed the holotype and a number of paratypes from the United States National Museum of Natural History. In every case for which characters of the material examined differed from the original description, the type material matched our initial observations rather than the description. This discrepancy could be explained if C. labiosa is variable in some characters, but we have not seen notable variation among the material we have examined, except for the slight differences mentioned below dealing with elytral punctation. As stated above, material we have examined now includes a significant portion of the original type series.

White (1996) stated that C. labiosa has a tiny angulation behind each anterior corner of the pronotum, and he employed this character in his diagnostic key. In actuality, such an angulation is scarcely present, or entirely absent, in all the material we have examined. If this angulation were clearly present, the key would enable easy identification of the species. However, if workers using the key do not observe the angulation, as is most likely, misidentification will result. Through the part of the key dealing with species without the pronotal angulation, users will encounter several problematic characters that are either difficult to interpret in specimens of C. labiosa or are intermediate between the options given. Such problematic characters include the size, number, and position of punctures on the vertex

${ }^{1}$ Monte L. Bean Life Science Museum, Brigham Young University, Provo, UT 84602.

${ }^{2}$ Department of Plant and Animal Sciences, Brigham Young University, Provo, UT 84602. 


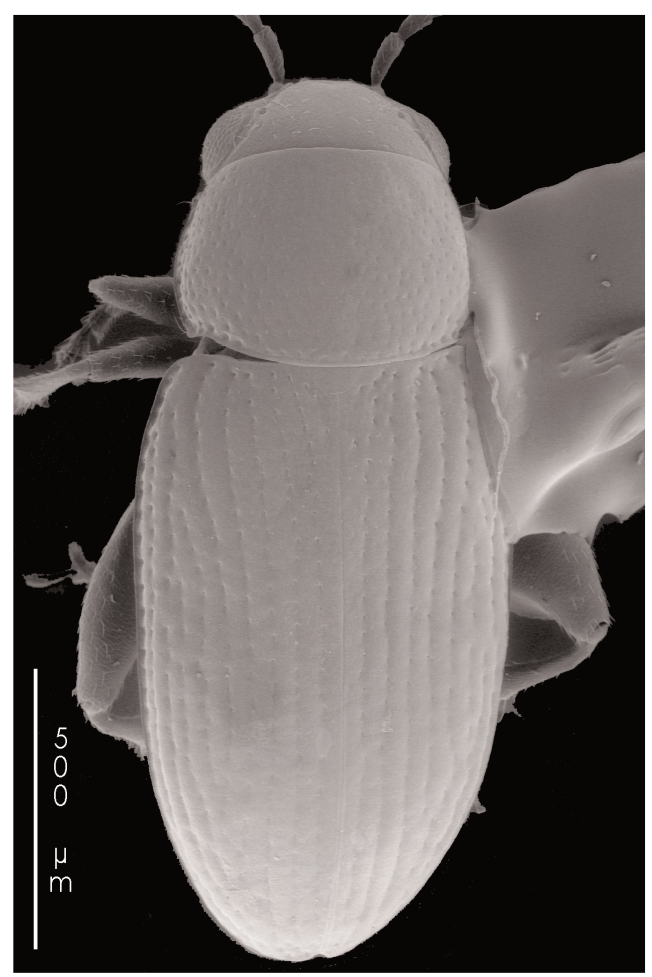

Fig. 1. Chaetocnema labiosa, dorsal habitus, SEM.

and pronotum; the overall body length; and the ratio of body length to body width. Fortunately, despite the problematic key, C. labiosa may immediately be recognized by the unique form of the labrum that is medially incised along the distal margin and therefore bilobed (Fig. 3).

Chaetocnema labiosa, at least from the material we have examined, is incapable of flight. White (1996) did not mention this, nor any of the characters associated with flightlessness. In fact, he stated that the humeri are normal. To the contrary, the humeri of all specimens we have examined are typical of flightless beetles, not being at all elevated (Fig. 2). In his description, White (1996) did not mention the metasternum. In specimens we have examined, it is conspicuously shortened (Fig. 4), again as is typical of flightless beetles. The distance separating the middle and hind coxal cavities is approximately the same as the frontto-back diameter of the mesocoxal cavity. In a similar species, $C$. densa, this distance is approximately 1.5 times this diameter. We removed the elytra of 5 specimens of C. labiosa and found the hind wings to be entirely absent.

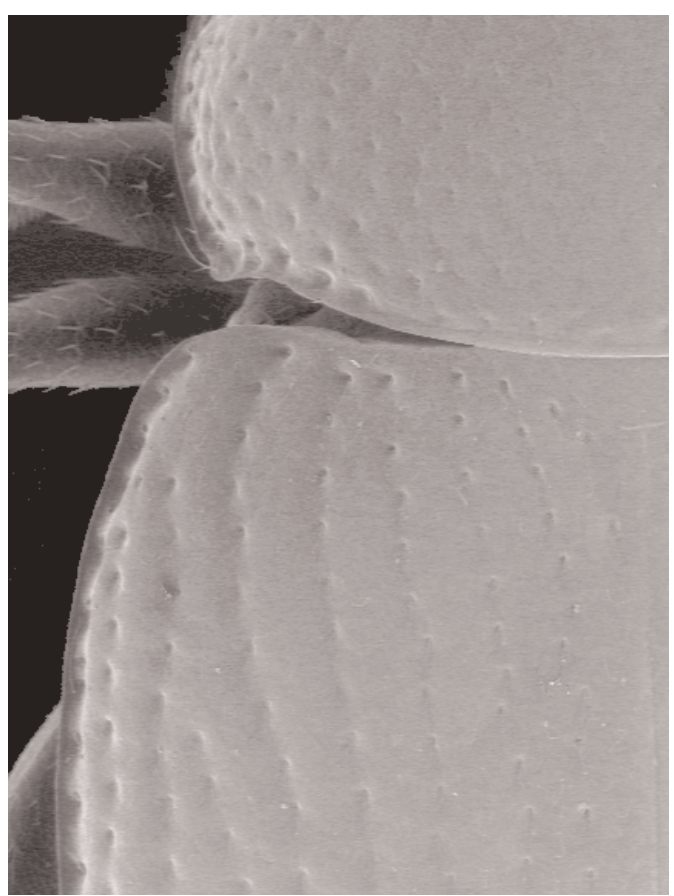

Fig. 2. Chaetocnema labiosa, posterolateral area of pronotum and humeral area of elytron, SEM.

White (1996) stated that the elytral striae are distinct and well aligned throughout. This character is actually variable. In many of the specimens we have seen, striae in the posthumeral area are irregular, although they are indeed regular in some of the material examined.

The following collection data supply new distributional information for this species, including a new state record for Wyoming. Acronyms are defined as follows: BYUC, Brigham Young University collection, Provo, Utah; EGRC, the private collection of Edward G. Riley, College Station, Texas; and USNM, United States National Museum of Natural History, Washington, DC.

Material EXAMINED.-Colorado: Mesa Co., Mack, 19 June 1933, G.F. Knowlton (male holotype, USNM); Saguache Co., $8 \mathrm{mi} \mathrm{N}$ Hooper, 11 July 1995, E.G. Riley (7 females, EGRC). Idaho: Bonneville Co., $23 \mathrm{mi} W$ Idaho Falls, G.E. Bohart (1 female paratype dated 8 July 1975 and collected from Artemisia, 1 female paratype dated 17 July 1975 and collected from Thelypodium sagittatum, USNM). Utah: Beaver Co., Milford, 7 July, Wickham (3 female paratypes, 1 of the specimens with 


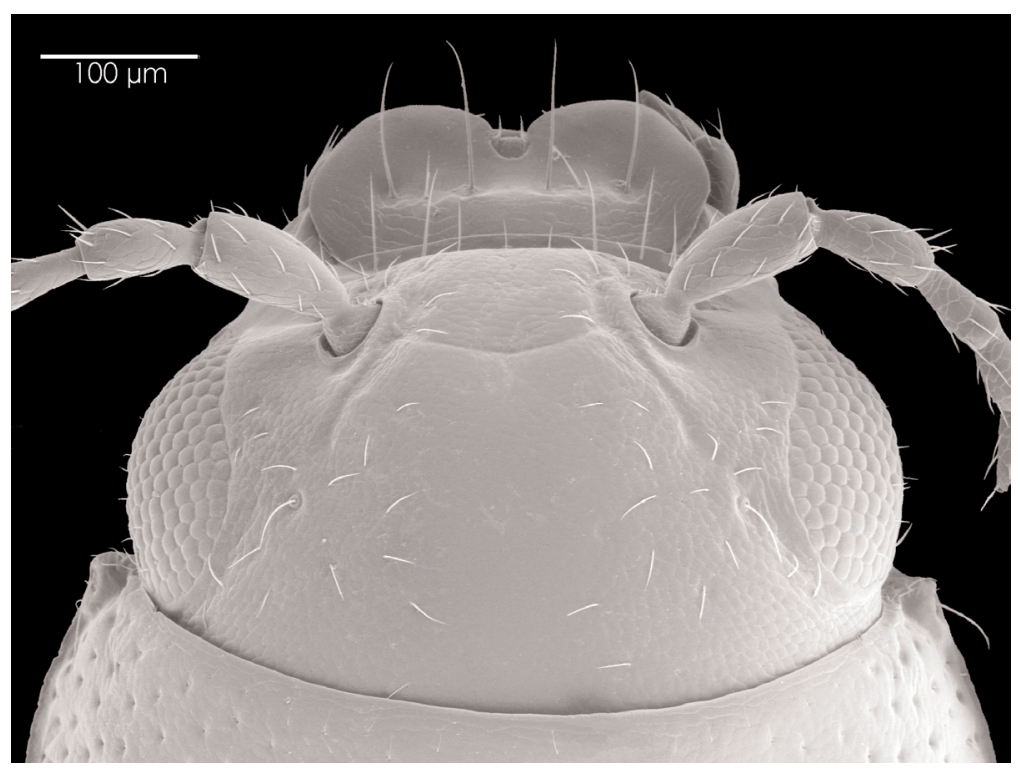

Fig. 3. Chaetocnema labiosa, head, SEM. Note bilobed labrum.

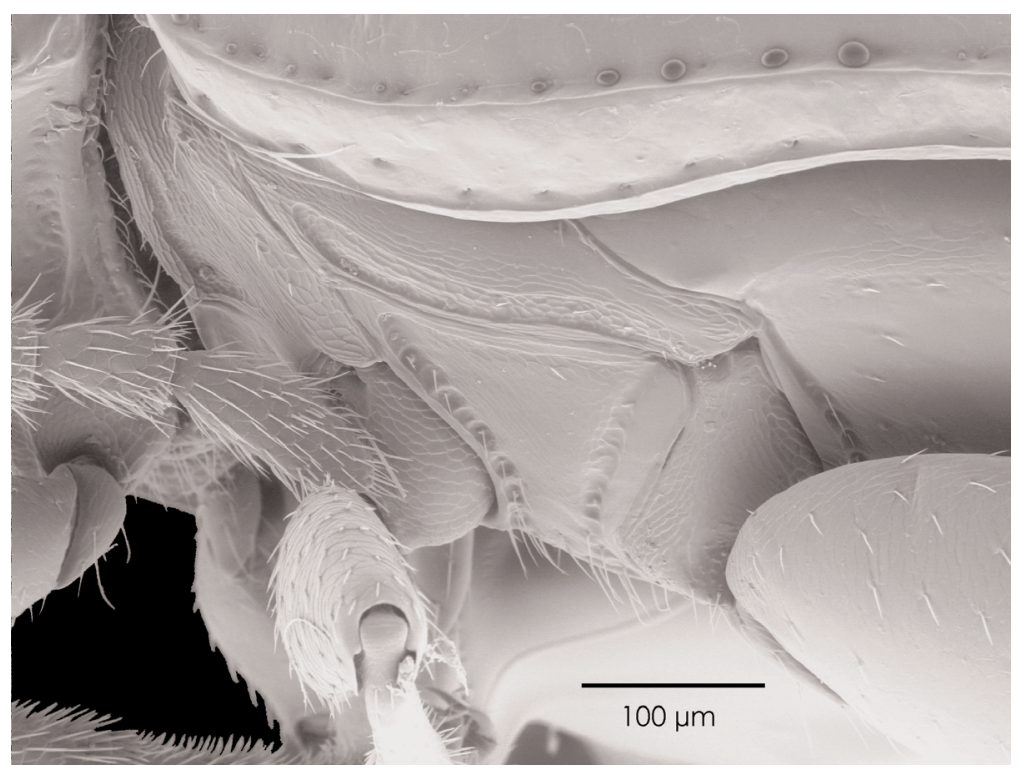

Fig. 4. Chaetocnema labiosa, lateral aspect of metathoracic area, SEM. Note short metasternum.

question marks on the collection label, the other 2 without question marks, USNM); Sanpete Co., Thistle Creek, near Coyote Springs, 26 June 1993, S.M. \& R.L. Clark (5 females, BYUC); Tooele Co., 5 mi S James Ranch, Gov't. Creek, Lowell Miller (1 female dated 12 June
1946, 1 female dated 17 June 1946, BYUC); Utah Co., Colton, 15 June 1939, H.P. Chandler (1 female, BYUC); Utah Co., West Mountain, $40.098^{\circ} \mathrm{N}, 111.826^{\circ} \mathrm{W}$, elevation $6450 \mathrm{ft}$., $24-$ VI-2005, S.M. Clark \& R.L. Johnson (92 females, BYUC; 5 females, EGRC; 5 females, 
USNM); Wyoming: Sweetwater Co., Seedskadee N.W.R., 5 July 1997, S.M. Clark (1 female, BYUC).

The West Mountain specimens listed above are noteworthy. The beetles were restricted to a $10-\mathrm{m}^{2}$ area. They were not found anywhere else, in spite of extensive observation in the vicinity. They were incredibly abundant within the aggregation area. Although only 102 specimens were kept, thousands could have been collected in just a few minutes.

The beetles in this aggregation primarily occurred on 4 plant species: Chrysothamnus nauseosus (Pallas) Britton, C. viscidiflorus (Hooker) Nuttall, Elymus spicatus (Pursh) Gould, and Poa fendleriana (Steudel) Vasey. It was unclear which, if any, of these was the host. In White's (1996) revision, he reported 2 specimens from Artemisia tridentata Nuttall and 1 other specimen from an undetermined species of Artemisia. He did not report any other plant associations. However, 1 of the paratype labels indicates that the specimen was collected from Thelypodium sagittatum (Nuttall) Englicher in Walpers, as can be seen in the above list of material we have examined. This plant is now known as Thelypodiopsis sagittata (Nuttall) O.E. Schulz (Welsh et al. 2003). It may be significant that Artemisia belongs to the same family, Asteraceae, as does Chrysothamnus.

It is interesting that all of the specimens listed above are females, except for the male holotype. The scarcity of males among the material we have examined, and especially in the large aggregation, suggests the possibility of asexual reproduction in some populations. Parthenogenesis in the Chrysomelidae has been reported for very few species, but some reports do involve the genus Chaetocnema, specifically C. confinis Crotch and C. perplexa Blake (Furth 1994, Cox 1996). As stated by Jolivet (2004), these 2 names are probably synonyms of each other. Beyond parthenogenesis, sexual reproduction (or at least populations that include males) also occurs in C. confinis and C. perplexa.

We gratefully acknowledge Alexander S. Konstantinov of the United States National Museum of Natural History, who initially compared material from the original type series of C. labiosa with specimens we sent to him, and who later loaned us type material so we could compare the specimens firsthand. We also acknowledge Edward G. Riley of College Station, Texas, who loaned material from his private collection.

\section{Literature Cited}

Cox, M.L. 1996. Parthenogenesis in the Chrysomeloidea. Pages 133-151 in P.H.A. Jolivet and M.L. Cox, editors, Chrysomelidae biology. Volume 3: general studies. SPB Academic Publishing, Amsterdam, The Netherlands.

FurTh, D.G. 1994. A new case of parthenogenesis in beetles: Longitarsus melanurus (Melsheimer) (Coleoptera: Chrysomelidae). Journal of the New York Entomological Society 102:310-317.

Jolivet, P. 2004. Sweetpotato flea beetle, Chaetocnema confints [sic] (Coleoptera Chrysomelidae Alticinae). Pages 225-227 in J.L. Capinera, editor, Encyclopedia of entomology. Kluwer Academic Publishers, Dordrecht, The Netherlands.

Welsh, S.L., N.D. ATwood, S. Goodrich, AND L.C. HigGins. 2003. A Utah flora. 3rd edition, revised. Brigham Young University, Provo, UT. 912 pp.

White, R.E. 1996. A revision of the genus Chaetocnema of America north of Mexico (Coleoptera: Chrysomelidae). Contributions of the American Entomological Institute 29:1-158.

Received 13 June 2006 Accepted 27 October 2006 